\title{
Anticonvulsant treatments of dysphoric mania: a trial of gabapentin, lamotrigine and carbamazepine in Iran
}

\author{
Naghmeh Mokhber' \\ Carol J Lane ${ }^{2}$ \\ Mohamad R Azarpazhooh ${ }^{3}$ \\ Elham Salari ${ }^{4}$ \\ Reza Fayazi ${ }^{5}$ \\ Mohamad T Shakeri ${ }^{6}$ \\ Allan $\mathrm{H}_{\text {Young }}{ }^{7}$ \\ 'Assistant Professor of Psychiatry, \\ ${ }^{3}$ Assistant Professor of Neurology, \\ ${ }^{4}$ Mashhad Department of Forensic \\ Psychiatry, ${ }^{5}$ Assistant Professor of \\ Psychiatry, ${ }^{6}$ Assistant Professor \\ of Statistics, Mashhad University \\ of Medical Science, Mashhad, Iran; \\ ${ }^{2}$ Department of Psychiatry, University \\ of British Columbia, Vancouver, \\ Canada $^{7}$
}

\begin{abstract}
The treatment of dysphoric mania is challenging given the need to treat symptoms of both depression and mania simultaneously without provoking any clinical exacerbation. The newer antiepileptic drugs such as gabapentin, lamotrogine, and carbamazepine are often used as adjuncts to either lithium or valproic acid in the treatment of bipolar disorder. We decided to undertake a monotherapy trial because previous evidence suggested mixed states may be more responsive to anticonvulsants than more traditional antimanic agents. 51 patients with a DSM IV diagnosis of dysphoric mania were randomized to three groups comprising gapbapentin, lamotrogine or carbamazepine and followed for 8 weeks. Psychiatric diagnosis was verified by the structural clinical interview for the DSM-IV (SCID). The MMPI-2 in full was used to assess symptoms at baseline and 8 weeks. All three groups showed significant changes in MMPI-2 scores for depression and mania subscales. Gabapentin showed the greatest change in depression symptom improvement relative to lamotrogine and carbamazepine, respectively. Although manic symptoms improved overall, here were no differences between groups in the degree of manic symptom improvement.
\end{abstract}

Keywords: dysphoric mania, manic-depression, depression, anticonvulsant, mood stabilizer

\section{Introduction}

The simultaneous presence of both manic and depressive symptoms referred to as mixed manic state or dysphoric mania has long been recognized (Kraepelin 1921; McElroy et al 1992; Swann et al 1993; Akiskal et al 1998; Cassidy et al 1998; Dilsaver et al 1999). According to the DSM-IV, for the diagnosis of mixed manic state, two of four depressive symptoms in the setting of a manic syndrome appear to suffice and occurs in 50 percent of patients with bipolar disorder at some time (Akiskal 2005). Although dysphoric mania is a common disorder and the outcomes are generally poorer than pure manic and depressive episodes, little is known about how to treat such a condition and new evidence based strategies are needed.

Gabapentin, lamotrigine, and carbamazepine may be used either as monotherapies or as adjuncts to lithium and valproate, as there is some evidence that mixed states may be more responsive to anticonvulsants than more traditional anti-manic agents (Clothier et al 1992; McElroy et al 1992; Dilsaver et al 1993; Bowden 1995; Post et al 1996; Kruger et al 2005). The aim of this study is to determine the clinical effectiveness of gabapentin, lamotrogine, and carbamazepine in dysphoric mania.

The newer antiepileptic drugs such as lamotrigine and gabapentin show therapeutic benefits in bipolar disorder (Soutullo et al 1998; Berk 1999; Bowden et al 1999; Calabrese et al 1999; Sethi et al 2003) and generally have more favorable side effect profiles because of less weight gain, less drug interactions and less need for therapeutic monitoring 
compared with older agents (Marken and Pies 2006). Whilst the anticonvulsants show growing evidence for the treatment of depressive symptoms in patients with bipolar disorder, as is seen in lamotragine (Bowden 1998; Bowden et al 1999, 2003; Calabrese et al 1998, 1999; Macdonald and Young 2002; Yatham et al 2002; Ghaemi and Gaughan 2005; Muzina et al 2005) and gabapentin (Ghaemi et al 1998; Altshuler et al 1999; Perugi et al 1999; Sokolski et al 1999; Young et al 1999; Vieta et al 2000; Macdonald and Young 2002; Wang et al 2002), it should be noted that more recent research does not support the use of these agents as antimanic agents (Pande et al 2000; Maidment 2001; Bowden 2002; Calabrese et al 2002).

An important treatment challenge in dysphoric mania is to bring about improvement in depressive symptoms without provoking the onset of manic symptoms. The studies referred to above however, were not designed to specifically treat mixed states but instead all manic episodes. In most studies, patients with mixed states accounted for a small subset of a total number of patients and thus extrapolation of these results to dysphoric mania patients as a whole should be considered with caution given the paucity of trials in the literature regarding the treatment of depressive features in mania (Vieta et al 2000). Despite limited evidence, concomitant anticonvulsants are used frequently in mixed manic patients. Therefore, we designed this clinical trial to compare the efficacy of monotherapy with lamotrigine, carbamazepine, or gabapentin in patients with dysphoric mania.

The MMPI-2 was selected to measure clinical symptoms of mania and depression. The MMPI- 2 has been validated in Iran and multiple groups have received training at numerous academic centers resulting in excellent inter-rater reliability (Duckworth and Anderson 1995; Mootabi Pers Comm 1995). Unfortunately the YMRS was not validated at the time of this study and the HAM-D (Hamilton Rating Scale for Depression) was not used as a single measure incorporating both mania and depression scores was required. Furthermore, the MMPI-2 is known for cross-cultural sensitivity. This has provided an instrument with religious and cultural contexts, which may be more appropriate for an Iranian study (Butcher 2004). For this reason the MMPI-2 in combination with the SCID were chosen as structured instruments.

\section{Materials and methods}

\section{Subjects}

A total of 59 patients entered the double blind, fixed dose, randomized study. Eight subjects were discontinued from the study due to adverse events. A total of 51 subjects completed the study, including 28 women and 23 men. The subjects ranged in age from 18-60 years (Table 1). All patients were recruited from two academic psychiatric outpatient clinics, Ghaem and Avecina hospitals, in Mashad, Iran. All patients met DSM-IV criteria for dysphoric mania. Patients had a history of bipolar I disorder with at least one prior manic episode, and a recent mild to modest but not severe mixed manic attack. No patients had current psychotic features.

Subjects with any other DSM-IV diagnosis requiring psychopharmacological treatment were excluded from the study. Alcohol and substance dependence or use within 1 month prior to study start date, and use of psychotropic medication for 3 months prior to study start date were also excluded from the study. Women of childbearing potential who were without adequate contraception were also excluded from the study. Subjects did not differ significantly with regard to demographic variables including age, sex, or educational level.

All subjects required a minimum reading level of grade 8 comprehension to be included in the study and have enough compliance to answer the questions necessary to participate in the MMPI-2. Therefore patients in a stage of disorganized mania were excluded from the study. All subjects underwent a medical and neurological examination and a series of laboratory tests for safety. Informed written consent was obtained from all subjects. The protocol was approved by the ethics committee of Mashhad University of Medical Sciences, Mashad, Iran. The trial was performed in accordance with the declaration of Helsinki.

\section{Drug therapy}

Subjects were randomized to three groups, group 1 (gabapentin, $900 \mathrm{mg} /$ day, $\mathrm{N}=18$ ), group 2 (lamotrigine, $100 \mathrm{mg} /$ day, $\mathrm{N}=20$ ), and group 3 (carbamazepine, $600 \mathrm{mg} /$ day $\mathrm{N}=13$ ).

Table I Patient baseline characteristics in an 8-week, randomized, single-blind trial of carbamazepine, lamotrigine, and gabapentin for treatment of dysphoric mania

\begin{tabular}{|c|c|c|c|}
\hline $\begin{array}{l}\text { Gabapentin } \\
(\mathbf{N}=18)\end{array}$ & $\begin{array}{l}\text { Lamotrigine } \\
(\mathbf{N}=\mathbf{2 0})\end{array}$ & $\begin{array}{l}\text { Carbamazepine } \\
(N=13)\end{array}$ & Characteristic \\
\hline $28.94 \pm 10.63$ & $27.80 \pm 7.65$ & $28.92 \pm 9.58$ & $\begin{array}{l}\text { Age (years) } \\
(\text { Mean } \pm S D)\end{array}$ \\
\hline $9 / 9$ & $11 / 9$ & $8 / 5$ & Female/male \\
\hline $48.33 \pm 8.48$ & $37.80 \pm 9.03$ & $42.08 \pm 8.63$ & $\begin{array}{l}\text { Depression } \\
\text { scores* } \\
\text { (Mean + SD) }\end{array}$ \\
\hline $26.11 \pm 3.14$ & $25.25 \pm 3.78$ & $24.85 \pm 2.07$ & $\begin{array}{l}\text { Mania score** } \\
(\text { Mean + SD) }\end{array}$ \\
\hline
\end{tabular}

Abbreviations: MMPI-2, Minnesota Multiphasic Personality Inventory-2; N, number of patients who completed the study; SD, standard deviation.

Notes: *Depression scores of depression subscale in MMPI-2 test; **Mania score of hypomania subscale in MMPI-2 test. 
Carbamazepin was in regular formation form. All three medications were initiated at low doses, Patients received carbamazepine $400 \mathrm{mg}$ /day (twice-daily dosing), lamotrigine $25 \mathrm{mg}$ /day at night and gabapentin $300 \mathrm{mg}$ /day divided in three doses. The doses of carbamazepine, lamotrigine and gabapentin were increased to a target dose of 600, 100 and $900 \mathrm{mg} /$ day, respectively within 2 weeks at which remained fixed until the end of study. Clinical assessments were carried out at the first visit (week 0), followed weekly until visit 3 (week 2 ) and then at 2-week intervals to visit 6 (8 weeks).

\section{Clinical assessment}

A detailed psychiatric interview by a psychiatrist was obtained at baseline and at the final visit. In addition, a structured clinical interview (SCID) was performed by a psychiatrist, with the patient and their family at the baseline visit. A single psychiatrist performed all ratings to reduce inter-rater error. In addition, patients with the assistance of their families filled out a questionnaire regarding gender, past medical and drug history, and other demographic information. Depression and mania symptoms were evaluated using subscales of the Minnesota multiphasic personality inventory 2 (MMPI-2). A single psychologist at baseline and at the final visit administered the 104-question test.

\section{Blinding}

Both the psychiatrist completing the interviews and the psychologist administering the MMPI-2 were blind to the treatment groups throughout the study period. Serum drug levels were not obtained in the study.

\section{Statistical analysis}

Only patients who had completed the study were included in demographic and efficacy analyses. Response to treatment regarding changes in depressive and manic scores was determined using analysis of variance (ANOVA). A t-test was used for comparisons of depression and mania scores between groups. For all analyses, $\mathrm{p}<0.05$ was defined as statistically significant. All statistical analyses were performed using SPSS version 11.

\section{Results}

The primary outcome measure was baseline versus endpoint change in the MMPI-2 scores.

\section{Total changes in depression and mania scores following 8 weeks treatment}

A significant change in mean total score on both the depression and mania subscales of MMPI-2 was observed following treatment for each of the three groups (Figures 1 and 2). The percent changes in depression scores for each of the three groups were as follows: gabapentin, 50\% decrease ( $\mathrm{p}<0.000)$, lamotrigine 33\% decrease $(\mathrm{p}<0.000)$, and carbamazepine $13 \%$ decrease $(\mathrm{p}<0.005)$. For carbamazepine, lamotrigine and gabapentin respectively, the percent change in mania score for each of the three groups were as follows: gabapentin $75 \%$ decrease $(\mathrm{p}<0.000)$, lamotrigine $64 \%$ decrease $(\mathrm{p}<0.000)$, and carbamazepine 59\% decrease $(\mathrm{p}<0.000)$ (Tables 2 and 3$)$.

\section{Between group differences: depression and mania symptoms}

There was a significant $(\mathrm{p}<0.05)$ effect on total mania score improvement in all three groups. The mean change of total mania scores on hypomania subscale in MMPI-2 test was greater in gabapentin than carbamazepine $(p=0.046)$. The results were also analyzed in subdimensions of mania

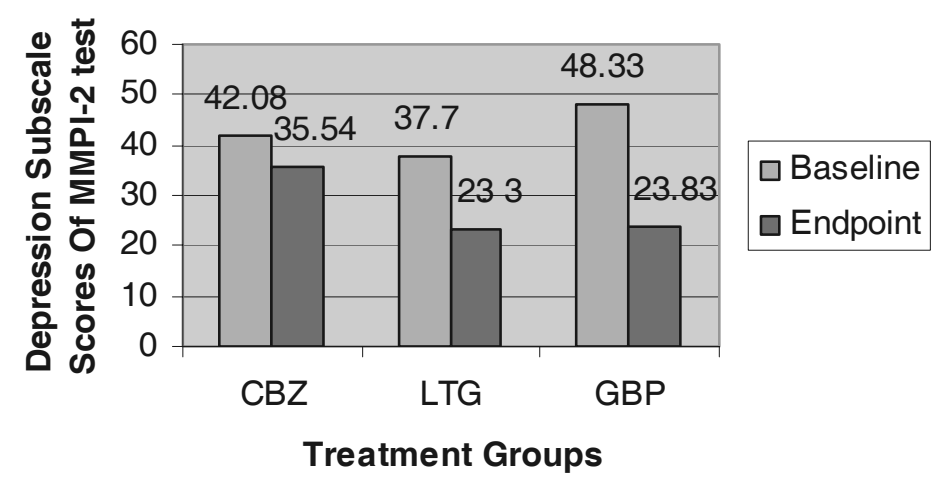

Figure I. Mean change of depression subscale of MMPI-2 test from the baseline to the endpoint in an 8-week, Randomized, Single-Blind Trial of Carbamazepine, Lamotrigine and Gabapentin for treatment of Dysphoric mania.

Abbreviations: MMPI-2, Minnesota Multiphasic Personality Inventory-2; CBZ, carbamazepine; LTG, lamotrigine; GBP, gabapentin. 


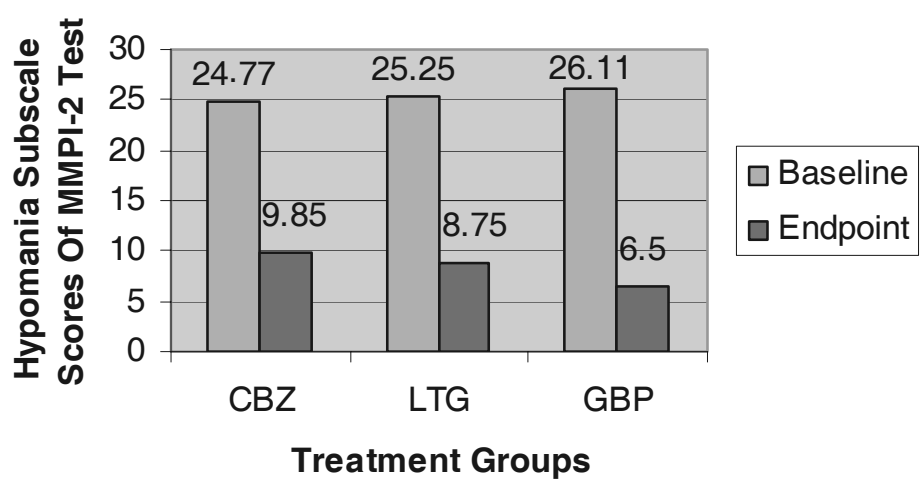

Figure 2. Mean change of mania subdimensions of hypomania subscale of MMPI-2 test from the baseline to the endpoint in an 8-week, Randomized, Single-Blind Trial of Carbamazepine, Lamotrigine and Gabapentin for treatment of Dysphoric mania.

Abbreviations: MMPI-2,Minnesota Multiphasic Personality Inventory-2; CBZ, carbamazepine; LTG, lamotrigine; GBP, gabapentin.

in MMPI-2 test, that showed a greater improvement in psychomotor acceleration (M2) in gabapentin than carbamazepine $(p=0.003)$. The improvement in other subdimensions of mania did not show statistically significant difference among groups (Table 4).

Significantly greater improvement in the mean total score on depression subscale of MMPI-2 test was observed in the gabapentin group when compared to lamotrigine $(\mathrm{p}=0.000)$ and in gabapentin and lamotrigine as compared to carbamazepine ( $\mathrm{p}=0.000, \mathrm{p}=0.040$, respectively) (Table 4).

\section{Depressive symptom subscale}

\section{assessment: gabapentin vs lamotrigine vs carbamazepine}

An additional analysis on the depression symptoms of each patient was completed to compare the three treatments (Figure 3). There are 5 subdimensions of the depression subscale. These subdimensions rate the following depressive symptoms: D1 subjective depression, D2 psychomotor retardation, D3 body dysfunction, D4 mental dullness, D5 brooding.

Treatment effects in 5 subdimensions of depression subscale in MMPI 2 test showed that improvement in the mean scores of psychomotor retardation and body dysfunction
(D2 and D3) were significantly greater in gabapentin and lamotrigine than in carbamazepine $(\mathrm{p}=0.023$ and $\mathrm{p}=0.0031$ in $\mathrm{D} 2$, and $p=0.000$ and $p=0.000$ in $\mathrm{D} 3$, respectively). In the carbamazepine group, the mean scores on these subdimensions of depression increased by 0.85 in psychomotor retardation and 1.15 in body dysfunction, indicating the condition was worsened. Improvements in the mean scores of mental dullness and brooding (D4 and D5) were significantly greater $(\mathrm{p}<0.01)$ in gabapentin than lamotrigine and carbamazepine.

\section{Depression subscale: improvement in subjective depression scores}

As it is important to evaluate that the improvement in depression score is related to the change in depressive associated symptoms or to the depressive mood itself, we analyzed the efficacy of drugs in reducing depressed mood (MMPI-2 subscale D1: subjective depression) scores and compared it with other subdimensions of depression subscale in MMPI-2. Mean percentage improvement in the depression subdimensions of depression subscale in MMPI-2 test showed greater improvement in depressed mood (D1-subjective depression) than other subdimenions of depression (Figure 3).

Table 2 Mean percentage change of depression and hypomania subscales of MMPI-2 test from the baseline to the endpoint in an 8-week, randomized, single-blind trial of carbamazepine, lamotrigine, and gabapentin for treatment of dysphoric mania

\begin{tabular}{|c|c|c|c|c|c|}
\hline \multicolumn{2}{|c|}{ Change \% (Mean percentage) } & \multicolumn{2}{|l|}{ After therapy } & \multicolumn{2}{|l|}{ Before therapy } \\
\hline Hypomania scores & Depression scores & $\begin{array}{l}\text { Hypomania scores } \\
\text { (Mean } \pm \text { SD) }\end{array}$ & $\begin{array}{l}\text { Depression scores } \\
\text { (Mean } \pm \text { SD) }\end{array}$ & $\begin{array}{l}\text { Hypomania scores } \\
\text { (Mean } \pm \text { SD) }\end{array}$ & $\begin{array}{l}\text { Depression scores } \\
\text { (Mean } \pm \text { SD) }\end{array}$ \\
\hline $74.98 \pm 13.06$ & $50.02 \pm 11.48$ & $6.50 \pm 3.60$ & $23.83 \pm 5.66$ & $26.11 \pm 3.14$ & $48.33 \pm 8.48$ \\
\hline $64.69 \pm 12.19$ & $33.45 \pm 15.44$ & $8.75 \pm 2.65$ & $23.30 \pm 4.74$ & $25.25 \pm 3.78$ & $37.70 \pm 9.03$ \\
\hline $58.80 \pm 25.70$ & $13.56 \pm 15.64$ & $9.85 \pm 5.56$ & $35.54 \pm 5.50$ & $24.77 \pm 2.00$ & $42.08 \pm 8.62$ \\
\hline
\end{tabular}

Abbreviations: MMPI-2, Minnesota Multiphasic Personality Inventory-2; SD, standard deviation. 
Table 3 Between group differences in mean percentage change of depression and hypomania subscales of MMPI-2 test scores analyzed with ANOVA test

\begin{tabular}{llll}
\hline Measure & Mean square & $\mathrm{F}$ & Sig \\
Depression* & 5025.88 & 24.85 & $0.00^{*}$ \\
mania** & 1062.73 & 7.38 & $0.03^{*}$ \\
\hline
\end{tabular}

Abbreviations: ANOVA, Analysis of Variance; F, F ratio; MMPI-2, Minnesota Multiphasic Personality Inventory-2; Sig, significance.

Notes: *Depression scores of depression subscale in MMPI-2 test; **Mania score of hypomania subscale in MMPI-2 test.

\section{Baseline differences}

There were no demographic differences found between groups in age, gender or educational level. There were no differences in baseline mania scores between groups however there were differences in baseline depression scores between groups (Table 5). The total depression subscale of the MMPI-2 was significantly higher in the gabapentin than lamotrigine group ( 48.33 vs $37.80 p=0.002$ ). This effect was also seen across all subdimension scores on the depression subscale of the MMPI-2. Carbamazepine depression scores at baseline were also higher than lamotrigine scores, though not significantly higher.

\section{Rescue medication}

Lorazepam up to $4 \mathrm{mg} /$ day was permitted for the management of agitation or insomnia only during the first two weeks of the study. No other adjunctive psychotropic medications were permitted during the study.

\section{Safety}

Safety ratings were carried out at the first visit, followed weekly until visit three and then at 2 week intervals to visit 6 (8 weeks). Safety ratings included assessment of vital signs and adverse events detected by clinical evaluation and spontaneous reports of patients and their families at each visit. Laboratory tests were conducted at baseline of the study and included: blood count, fasting blood sugar, liver function tests, electrolytes, blood urea nitrogen, serum creatinine, thyroid function test, and urine analysis. Eight subjects were withdrawn from the study due to adverse events. Six subjects (31\%) withdrew from the carbamazepine group due to gastrointestinal upset and/or vertigo and 2 subjects (11\%) withdrew from the gabapentin group due to severe drowsiness and/or skin itching.

\section{Discussion}

Anticonvulsant therapy using gabapentin, lamotragine, or carbamazepine is effective in the treatment of mild to moderate dysphoric mania. All treatments showed significant improvement in depression and mania symptoms relative to baseline. Gabapentin showed the greatest change in depression symptom improvement relative to lamotrigine and carbamazepine, respectively. There were no significant differences between groups in manic symptom improvement.

To our knowledge, this is the first study to systematically evaluate monotherapy with carbamazepine, lamotrigine, and gabapentin in patients with dysphoric mania. Indeed this is one of the first randomized fixed dose trials observing the three anticonvulsants in an 8 week trial using validated clinical instruments in Iran. The study concluded that monotherapy with gabapentin, lamotrigine and carbamazepine was effective treating mixed states as shown by significant changes to the MMPI following treatment and the effects of gabapentin were superior to lamotrigine and lamotrigine was superior to carbamazepine. However in the absence or a parallel placebo control group we cannot conclude that this effectiveness is equivalent to efficacy.

In our study gabapentin provided significantly greater symptom improvement in depression scores than lamotrigine. This finding is in accordance with Sokolski and colleagues (1999) who showed a rapid action of gabapentin against the depressive symptoms of the mixed state. Numerous studies have reported the benefits of lamotrigine on depressive symptoms (Bowden 1998; Bowden et al 1999, 2003; Calabrese

Table 4 Between group differences in mean change of depression and hypomania subscale of MMPI-2 test scores analyzed with ANOVA test

\begin{tabular}{llll}
\hline Measure & Mean square & F & Sig \\
\hline $\begin{array}{l}\text { DI - Subjective } \\
\text { Depression score }\end{array}$ & 87.43 & 2.27 & 0.11 \\
$\begin{array}{l}\text { D2 - Psychomotor } \\
\text { Retardation score }\end{array}$ & 57.93 & 4.50 & $0.02^{*}$ \\
$\begin{array}{l}\text { D3 - Body Dysfunction } \\
\text { score }\end{array}$ & 81.40 & 16.13 & $0.00^{*}$ \\
$\begin{array}{l}\text { D4 - Mental Dullness } \\
\text { score }\end{array}$ & 88.37 & 6.77 & $0.003^{*}$ \\
$\begin{array}{l}\text { D5 - Brooding score } \\
\text { Total Depression }\end{array}$ & 42.79 & 7.26 & $0.002^{*}$ \\
$\begin{array}{l}\text { subscale score } \\
\text { MI - Amorality score }\end{array}$ & 1290.71 & 21.34 & $0.00^{*}$ \\
$\begin{array}{l}\text { M2 - Psychomotor } \\
\text { Acceleration score } \\
\text { M3 - Imperturbability }\end{array}$ & 0.243 & 0.08 & 0.92 \\
$\begin{array}{l}\text { score } \\
\text { M4 - Ego Inflation }\end{array}$ & 42.65 & 6.25 & $0.004^{*}$ \\
$\begin{array}{l}\text { score } \\
\text { Hypomania subscale }\end{array}$ & 11.11 & 0.05 & 0.95 \\
score & 90.92 & 2.22 & 0.12 \\
\hline AbrevionsANOVA,Anatys & & 3.31 & $0.04^{*}$ \\
\hline
\end{tabular}

Abbreviations:ANOVA, Analysis of Variance; F, F ratio; MMPI-2, Minnesota Multiphasic Personality Inventory-2; Sig, significance. 


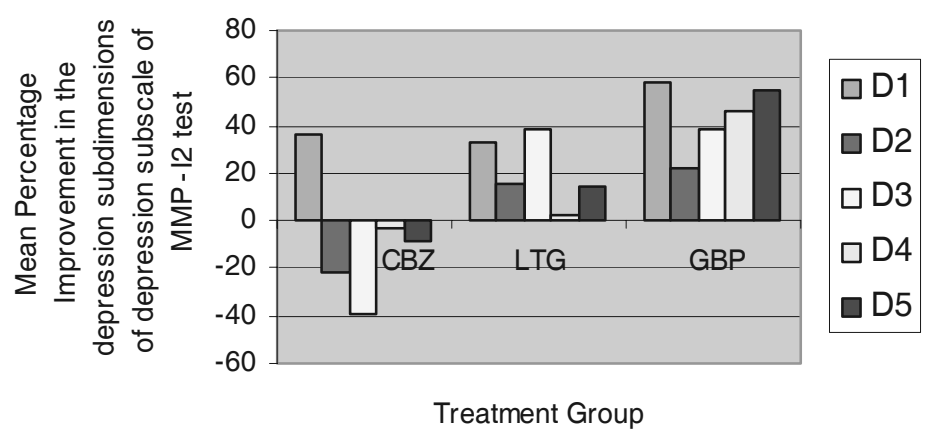

Figure 3. Mean Percentage Improvement in the depression subdimensions of depression subscale in MMPI-2 test in an 8-week, Randomized, Single-BlindTrial of Carbamazepine, Lamotrigine and Gabapentin for treatment of Dysphoric mania.

Abbreviations: MMPI-2, Minnesota Multiphasic Personality Inventory-2; CBZ, carbamazepine; LTG, lamotrigine; GBP, gabapentin; DI, Subjective Depression; D2, Psychomotor Retardation; D3, Body dysfunction; D4, Mental Dullness; D5, Brooding.

et al 1998, 1999; Macdonald and Young 2002; Yatham et al 2002; Ghaemi and Gaughan 2005; Muzina et al 2005), and indeed lamotrigine was effective in the treatment of depressive symptoms in our study. The reason why gabapentin may have superceded lamotrigine in our study might be related to a lower baseline depression score in lamotrigine group, thus leaving little room for symptom improvement.

Gabapentin was superior to carbamazepine for reducing depression and mania symptoms. Although some trials fail to show clear antimanic efficacy of gabapentin (Carta et al 2003), Erfruth and colleagues (1998) and Grunze and colleagues (1999) suggest that monotherapy with gabapentin might be useful in selected patients to treat modest but not severe manic states. Our study suggests that gabapentin may be helpful for the treatment of depression in some bipolar patients.

Of particular concern in our study were earlier reports have suggested an association between lamotrigine and gabapentin use and subsequent manic or hypomanic episodes (Short and Cooke 1995; Leweke et al 1999; Margolese et al 2003). However, most of these reports were isolated events influenced by a variety of confounding factors. In our study, lamotrigine and gabapentin were well tolerated and there was no evidence of exacerbation of manic symptoms. Moreover, all of these agents were more effective on manic symptoms than depressive symptoms (Figures 1 and 2) as shown by the mean percentage decrease in total depression and mania scores.

In our study, carbamazepine, lamotrigine, and gabapentin had a clear effect on depressed mood (D1 - subjective depression). Therefore the improvement in depression score was due to a real improvement in depressive mood, not merely in depressive associated symptoms. This finding is support by Baker and colleagues (2003) on a reanalysis of the two studies performed by Tohen and colleagues $(1999,2000)$ who showed that the use of olanzapine in reducing total HAM-D scores was more directed to reducing somatic and paranoid symptoms than to depressive mood itself.

Our study has several limitations and include: lack of a control group, no comparison to valproate or lithium, use of the MMPI as a clinical instrument instead of the YMRS or the HAM-D, randomization imbalances due to dropouts, variance in severity of depression scores at baseline between groups,

Table 5 Between group differences in baseline depression and hypomania subscales of MMPI-2 test scores analyzed with ANOVA test

\begin{tabular}{llll}
\hline Measure & Mean square & F & Sig \\
\hline $\begin{array}{l}\text { DI - Subjective } \\
\text { Depression score }\end{array}$ & 52.65 & 1.16 & 0.323 \\
$\begin{array}{l}\text { D2 - Psychomotor } \\
\text { Retardation score }\end{array}$ & 7.83 & 0.85 & 0.433 \\
$\begin{array}{l}\text { D3 - Body dysfunction } \\
\text { score }\end{array}$ & 27.39 & 6.58 & $0.003^{*}$ \\
$\begin{array}{l}\text { D4 - Mental dullness } \\
\text { score }\end{array}$ & 31.86 & 4.86 & $0.02^{*}$ \\
$\begin{array}{l}\text { D5 - Brooding score } \\
\text { Total Depression }\end{array}$ & 19.43 & & \\
subscale score & 528.02 & 4.86 & $0.012^{*}$ \\
$\begin{array}{l}\text { MI - Amorality score } \\
\text { M2 - Psychomotor }\end{array}$ & 0.87 & 6.92 & $0.002^{*}$ \\
$\begin{array}{l}\text { Acceleration score } \\
\text { M3 - Imperturbability }\end{array}$ & 21.34 & 0.67 & 0.518 \\
$\begin{array}{l}\text { score } \\
\text { M4 - Ego Inflation }\end{array}$ & 2.10 & 5.77 & $0.006^{*}$ \\
$\begin{array}{l}\text { score } \\
\text { Hypomania subscale } \\
\text { score }\end{array}$ & 0.34 & 1.53 & 0.294 \\
\hline Abreviatons:ANOVA, & 7.34 & 0.14 & 0.869 \\
\hline
\end{tabular}

Abbreviations: ANOVA, Analysis of Variance; F, F ratio; MMPI-2, Minnesota Multiphasic Personality Inventory-2; Sig, significance. 
relatively small sample size, low fixed dose of medication, and no serum drug levels were obtained.

In regard to the dose, we used a relatively low fixed dose of medication, in view of the subject selection criteria, which excluded patients in severe manic episode (that commonly are treated by adjunct therapy). However, all medications were within the therapeutic window of treatment for dosage. In addition, subjects were obtained from academic psychiatric outpatient clinics and may not be representative of community patients. Finally, we could not monitor the blood levels of the drugs due to local hospital limitations. Yet, despite all of these limitations we observed highly significant improvement from baseline following treatment in all three medication groups after 8 weeks, these results may therefore indicate effectiveness of these anticonvulsants in the monotherapy treatment of mild to moderate dysphoric mania.

In comparison with other studies in the field, our study had both strengths and weaknesses. For example, our study did not allow patients to titrate to maximal efficacy nor were serum blood levels obtained to compare with therapeutic efficacy. Unlike most other studies on the anticonvulsants we did not make comparisons to either lithium or valproic acid. Our study did have excellent inter-rater reliability and advanced training on the clinical instruments, a factor often missing in other studies. In addition there were no serious adverse events reported in the study. Finally the use of the YMRS (Young mania rating scale) as a measurement for end point analysis could have been a better choice had this option been available in Iran, as this instrument has been more commonly used to assess manic symptoms in the literature.

\section{Implications for further research}

Dysphoric mania is common, severe, and resistant to treatment, therefore further studies are warranted with larger sample sizes. Future studies should examine the effects of these anticonvulsants in monotherapy and in adjunct therapy with lithium and valproate. Further research is also needed to fully clarify the role of new agents with putative antidepressant properties. In addition psychiatric structured clinical interviews like the SCID when combined with psychological test batteries such as the MMPI provide validity for studies using clinical endpoint analysis in areas of cultural diversity.

\section{Acknowledgments}

This study was undertaken as the thesis of Dr Elham Salari for graduating in psychiatrics. Her study was supported by research committee of Mashad University of Medical
Sciences. The authors thank Dr Kamran Javidi Dashtbayaz and Dr Mohamad Taghi Shakeri for statistical analysis and participating in this study. Minnesota Multiphasic Personality Inventory-2 test evaluation and analysis was performed by Ms Shanz Sabouri.

\section{References}

Altshuler LL, Keck PE, McElroy SL, et al. 1999. Gabapentin in the acute treatment of refractory bipolar disorder. Bipolar Disord, 1:61-5.

Akiskal HS. 2005. Mood Disorders: Clinical Features. In: Sadock BJ, Sadock VA eds. Comprehensive Text Book of Psychiatry. 8th ed. Philadelphia: Lippincott Williams and Wilkins, p 1636.

Akiskal HS, Hantouche EG, Bourgeois ML, et al. 1998. Gender, temperament, and the clinical picture in dysphoric mixed mania: findings from a French national study (EPIMAN). $J$ Affect Disord, 50(2-3):175-86.

Baker RW, Tohen M, Fawcett J, et al. 2003. Acute dysphoric mania: treatment response to olanzapine versus placebo. J Clin Psychopharmacol, 23:132-7.

Berk M 1999. Lamotrigine and the treatment of mania in bipolar disorder. Eur Neuropsychopharmacol, 9(Suppl 4):S119-23.

Bowden CL, Calabrese JR, Sachs G, et al. 2003. A placebo-controlled 18-month trial of lamotrigine and lithium maintenance treatment in recently manic or hypomanic patients with bipolar I disorder. Arch Gen Psychiatry, 60:392-400.

Bowden CL. 2002. Lamotrigine in the treatment of bipolar disorder. Expert Opin Pharmacother, 3:1513-19.

Bowden CL, Calabrese JR, McElroy SL, et al. 1999. The efficacy of lamotrigine in rapid cycling and non-rapid cycling patients with bipolar disorder. Biol Psychiatry, 45:953-8.

Bowden CL, Mitchell P, Suppes T. 1999. Lamotrigine in the treatment of bipolar depression. Eur Neuropsychopharmacol, 9(Suppl 4): S113-17.

Bowden CL. 1998. New concepts in mood stabilization: evidence for the effectiveness of valproate and lamotrigine. Neuropsychopharmacology, 19:194-9.

Bowden CL. 1995. Predictors of response to divalproex and lithium. J Clin Psychiatry, 56(Suppl 3):25-30.

Butcher JN. 2004. Personality assessment without borders: adaptation of the MMPI-2 across cultures. J Pers Assess, 83:90-104.

Calabrese JR, Shelton MD, Rapport DJ, et al. 2002. Bipolar disorders and the effectiveness of novel anticonvulsants. J Clin Psychiatry, 65(Suppl 3):5-9.

Calabrese JR, Bowden CL, McElroy SL, et al. 1999. Spectrum of activity of lamotrigine in treatment-refractory bipolar disorder. Am J Psychiatry, 156:1019-23.

Calabrese JR, Bowden CL, Sachs GS, et al. 1999. A double-blind placebocontrolled study of lamotrigine monotherapy in outpatients with bipolar I depression. Lamictal 602 Study Group. J Clin Psychiatry, 60:79-88.

Calabrese JR, Rapport DJ, Shelton MD, et al. 1998. Clinical studies on the use of lamotrigine in bipolar disorder. Neuropsychobiology, 38:185-91.

Carta MG, Hardoy MC, Hardoy MJ, et al. 2003. The clinical use of gabapentin in bipolar spectrum disorders. J Affect Disord, 75:83-91.

Cassidy F, Murry E, Forest K, et al. 1998. Signs and symptoms of mania in pure and mixed episodes. J Affect Disord, 50(2-3):187-201.

Clothier J, Swann AC, Freeman T. 1992. Dysphoric mania. J Clin Psychopharmacol, 12(Suppl 1):13S-16S.

Dilsaver SC, Chen YR, Shoaib AM, et al. 1999. Phenomenology of mania: evidence for distinct depressed, dysphoric, and euphoric presentations. Am J Psychiatry, 56:426-30.

Dilsaver SC, Swann AC, Shoaib AM, et al. 1993. The manic syndrome: factors which may predict a patient's response to lithium, carbamazepine and valproate. $J$ Psychiatry Neurosci, 18:61-6. 
Duckworth JC, Anderson WP. 1995. MMPI and MMPI-2 Interpretation Manual for Counselors and Clinicians. Bristol, Pa, Accelerated Development.

Erfurth A, Kammerer C, Grunze H, et al. 1998. An open label study of gabapentin in the treatment of acute mania. J Psychiatr Res, 32:261-4.

Ghaemi SN, Gaughan S. 2005. Novel anticonvulsants: a new generation of mood stabilizers? Harv Rev Psychiatry, 8:1-7.

Ghaemi SN, Katzow JJ, Desai SP, et al. 1998. Gabapentin treatment of mood disorders: a preliminary study. J Clin Psychiatry, 59:426-9.

Grunze H, Erfurth A, Amann B, et al. 1999. Gabapentin in the treatment of mania. Fortschr Neurol Psychiatr, 67:256-60.

Ichim L, Berk M, Brook S. 2000. Lamotrigine compared with lithium in mania: a double-blind randomized controlled trial. Ann Clin Psychiatry, 12:5-10.

Kraepelin E. 1921. Manic-depressive insanity and paranoia. Edinburgh. E and S Livingstone.

Kruger S, Trevor Young L, Braunig P. 2005. Pharmacotherapy of bipolar mixed states. Bipolar Disord, 7:205-15.

Leweke FM, Bauer J, Elger CE. 1999. Manic episode due to gabapentin treatment. Br J Psychiatry, 175:291a.

Macdonald KJ, Young LT. 2002. Newer antiepileptic drugs in bipolar disorder: rationale for use and role in therapy. CNS Drugs, 16:549-62.

Maidment ID. 2001. Gabapentin treatment for bipolar disorders. Ann Pharmacother, 35:1264-9.

Margolese HC, Beauclair L, Szkrumelak N, et al. 2003. Hypomania induced by adjunctive lamotrigine. Am J Psychiatry, 160:183-4.

Marken PA, Pies RW. 2006. Emerging treatments for bipolar disorder: safety and adverse effect profiles. Ann Pharmacother, 40:279-85.

McElroy SL, Keck PE, Pope HG, et al. 1992. Clinical and research implications of the diagnosis of dysphoric or mixed mania or hypomania. Am J Psychiatry, 149:1633-44.

Mootabi F. 1995. Preparation and normalization of MMPI-2 questionnaire in Tehran city. Unpublished, personal communication.

Muzina DJ, Elhaj O, Gajwani P, et al. 2005. Lamotrigine and antiepileptic drugs as mood stabilizers in bipolar disorder. Acta Psychiatr Scand Suppl, 426:21-8.
Pande AC, Crockatt JG, Janney CA, et al. 2000. Gabapentin in bipolar disorder: a placebo-controlled trial of adjunctive therapy. Gabapentin Bipolar Disorder Study Group. Bipolar Disord, 2(3 pt 2):249-55.

Perugi G, Toni C, Ruffolo G, et al. 1999. Clinical experience using adjunctive gabapentin in treatment-resistant bipolar mixed states. Pharmacopsychiatry, 32:136-41.

Post RM, Ketter TA, Denicoff K, et al. 1996. The place of anticonvulsant therapy in bipolar illness. Psychopharmacology (Berl), 128:115-29.

Sethi MA, Mehta R, Devanand DP. 2003. Gabapentin in geriatric mania. J Geriatr Psychiatry Neurol, 16:117-20.

Short C, Cooke L. 1995. Hypomania induced by gabapentin. Br J Psychiatry, 166:679-80.

Sokolski KN, Green C, Maris DE, et al. 1999. Gabapentin as an adjunct to standard mood stabilizers in outpatients with mixed bipolar symptomatology. Ann Clin Psychiatry, 11:217-22.

Soutullo CA, Casto LS, Keck PE. 1998. Gabapentin in the treatment of adolescent mania: a case report. $J$ Child Adolesc Psychopharmacol, $8: 81-5$.

Swann AC, Secunda SK, Katz MM, et al. 1993. Specificity of mixed affective states: clinical comparison of dysphoric mania and agitated depression. J Affect Disord, 28:81-7.

Tohen M, Jacobs TG, Grundy SL, et al. 2000. Efficacy of olanzapine in acute bipolar mania: a double-blind, placebo-controlled study. Arch Gen Psychiatry, 57:841-9.

Tohen M, Sanger TM, McElroy SL, et al. 1999. Olanzapine versus placebo in the treatment of acute mania. Am J Psychiatry, 156:702-9.

Yatham LN, Kusumakar V, Calabrese JR, et al. 2002. Third generation anticonvulsants in bipolar disorder: a review of efficacy and summary of clinical recommendations. $J$ Clin Psychiatry, 63:275-83.

Young LT, Robb JC, Hasey GM, et al. 1999. Gabapentin as an adjunctive treatment in bipolar disorder. $J$ Affect Disord, 55:73-7.

Vieta E, Martinez-Aran A, Nieto E, et al. 2000. Adjunctive gabapentin treatment of bipolar disorder. Eur Psychiatry, 15:433-7.

Wang PW, Santosa C, Schumacher M, et al. 2002. Gabapentin augmentation therapy in bipolar depression. Bipolar Disord, 4:296-301. 